revista do ieb n 45 p. 21-36 set 2007

\title{
De Xarayes ao Pantanal: a cartografia de um mito geográfico
}

Maria de Fátima Costa ${ }^{1}$

Resumo

Neste artigo tem-se como foco a Laguna de los Xarayes. Trata-se de um mito geográfico que, como seus semelhantes os lagos Eupana, Eldorado ou Paytiti, teve longa vida: surgiu nos primeiros anos de 1600 e logo ganhou contornos cartográficos, aparecendo nos mapas como um grande lago ou lagoa, cujas proximidades eram habitadas por índios agricultores, de boa indole e possuidores de metais preciosos: os Xarayes. Com estas características, já no início do século XVII figurou nos Atlas neerlandeses, tornando-se a imagem constitutiva do interior sulamericano; a cartografia jesuítica também lhe rendeu tributos, representando Xarayes como o lugar onde nascia o rio Paraguai. Em meados do Setecentos, entretanto, demarcadores de limites e inacianos perceberam que a Laguna de los Xarayes nada mais era que as águas do Paraguai quando este rio espraiava-se, em tempos de suas cheias. Desde então aquele lugar passou a receber o nome de Pantanal.

\section{Palavras-chave}

Xarayes, Pantanal, jesuítas, demarcação de limites, cartografia. 
revista do ieb n 45 p. 21-36 set 2007

\title{
From Xarayes to Pantanal: the cartography of a geographical myth
}

Maria de Fátima Costa

\begin{abstract}
The subject of this article is the Laguna de los Xarayes, which represents a lasting geographical myth, like many others, as those of the lakes Eupana, Eldorado or Paytiti. It embodies a myth that appeared soon after 1600, and that was quickly incorporated in cartographical representations. On the maps it was drawn as a great lake or lagoon, in whose surroundings lived agriculture practicing Indians, lovely people who owned precious metals: they were the Xarayes. With such features it was already included in the early Dutch atlases, at the beginning of the 17th Century, becoming then a generally accepted component of the South American middle lands. Also the jesuitical cartography included it as the source of the river Paraguay. At the middle of the 18th Century, however, both by the commissioners in charge of the boundary settlement and the Jesuits recognized the Laguna de los Xarayes as the river Paraguay overflowing its banks during the rainy season. From then on this place was registered as the Pantanal.
\end{abstract}

\section{Keywords}

Xarayes, Pantanal, jesuits, boundary settlement, cartography. 
Um dos muitos mitos alusivos a lugares e riquezas americanas é o da Laguna de los Xarayes. Enrique de Gandia, no belo livro Historia critica de los mitos de la conquista americana, observa com propriedade que esta lagoa foi um dos focos de ilusão associados ao famoso mito do Eldorado ${ }^{2}$.

Como os seus semelhantes, dos lagos do Eldorado, do Paititi e do Eupana, o de Xarayes é um mito que teve longa vida: surgiu nos primeiros anos de 1600, quando Antonio de Herrera lhe deu identificação espacial, e já no final da década de 1620 ganhou contornos cartográficos graças ao empenho dos neerlandeses, que nas páginas de seus preciosos Atlas fizeram a Laguna de los Xarayes ter fisionomia própria. Esta imagem foi reproduzida em diferentes mapas e caracterizou o interior sulamericano até o final do século XVIII. É sobre esta lagoa que aqui se falará.

Ao conceituá-la como mito geográfico, temos como referência a definição dada por Jaime Cortesão, que, no seu estudo sobre Raposo Tavares ${ }^{3}$, analisa o mito da Ilha-Brasil: um fenômeno relacionado a uma época heróica, concebido pela intuição de uma realidade mal conhecida. Segundo Cortesão, os mitos geográficos correspondiam a uma necessidade de ação e estimularam grandes empreendimentos. Estudando a história da conquista sul-americana, percebe-se que tal foi a empresa que os castelhanos realizaram na primeira metade do século XVI na região fluvio-lacustre do Paraguai.

De fato, a história de Xarayes está intimamente ligada à história do rio Paraguai. Suas águas foram o eixo da penetração e colonização da região e, mais ainda, acreditou-se durante muito tempo que a lagoa fosse a própria nascente do Paraguai, conforme os missionários jesuítas sugeriram em seus textos e mapas. Era dali - diziam estes religiosos - que vertiam as águas desse rio. Este mesmo lugar é o que hoje denominamos Pantanal.

\section{Surgimento de Xarayes}

Já nas primeiras entradas às terras da bacia do Prata, os espanhóis começaram a descrever a região. Nas suas narrativas aparecem, entre outros indígenas, os Xarayes, povo que habitava as duas margens de um trecho do rio Paraguai. Por

2 GANDIA, Enrique. Historia critica de los mitos de la conquista americana. Madrid: Juan Roldán y Compañía, 1909.

3 CORTESÃO, Jaime. Raposo Tavares e a formação territorial do Brasil. Lisboa: Portugalia Editora, 1966. 2 v. (1º edição de 1958). 
extensão, Xarayes se transformou em topônimo, surgindo assim a região de Xarayes, registrada como um lugar fértil, inundável, entrecortado por muitos rios, lagos e baías. As suas primeiras referências escritas encontram-se na Relación do conquistador Domingo Martínez de Irala e datam de $1542^{4}$. Em breve a região tornar-se-ia conhecida no Ocidente, inicialmente a partir dos Comentários, publicados em 1555 pelo segundo governador e adelantado do Rio de la Plata, Álvar Núñez Cabeza de Vaca ${ }^{5}$, e depois pela narrativa que o soldado alemão a serviço de Espanha, Ulrico Schmidl, trouxe a público em 1567, na qual contava suas andanças de quase vinte anos nas "Novas Índias de Castela"6. Naquelas descrições, as terras e águas alto-paraguaias são roteiros a serem perseguidos: as lagoas e baías são portos, enquanto os rios são vias de entrada.

0 grande personagem dessas narrativas é o rio Paraguai. Foi subindo o seu caudaloso curso que as embarcações espanholas viajaram rumo ao interior do continente. Vale lembrar que o motor da conquista era o sonho constante da busca de riquezas. Assim, o interesse em remontar as águas paraguaias estava ligado a esse objetivo. 0 Paraguai poderia ser o caminho que levaria aos lugares habitados pelo "Rei Branco", nos quais havia uma "Montanha Prateada", ali onde se dizia existiam grandes e ricas cidades; o lugar das "notícias”. E foi em busca destas notícias que os espanhóis remontaram as águas do Paraguai e empreenderam a conquista da América Meridional.

Assim, o caminho das entradas e também das narrativas é o rio Paraguai. Foi a partir dele que se descreveu o entorno. Seguindo seu curso, em 1543, Domigo Martínez de Irala alcançou um lugar abrigado ao qual, por ser o dia 6 de janeiro, deu o nome de Puerto de los Reyes, na região do complexo fluvio-lacustre de

4 MARTÍNEZ DE IRALA, Domingo. Relación de Domingo Martínez de Irala acerca de los descubrimientos que iba haciendo cuando fue navegando Paraguay arriba por orden del gobernador Cabeza de Vaca, desde 18 de diciembre de 1542. Anales de la Biblioteca, Buenos Aires, Biblioteca Nacional, t.8, 1912 .

5 CABEZA DE VACA, Álvar Núñez. Naufragios y comentarios. Madrid: Anaya y Oronoz, 1992. [La relación y comentarios del gouvernador Aluar Nuñez cabeza de vaca, de lo acaescido en las dos jornadas que hizo a las Indias. Valladolid, 1555]

6 SCHMIDL, Ulrico. Warhrafftige historien einer wunderbaren schiffart. Graz: Akademische Druck-und Verlagsanstalt, 1962. [Ander theil dieses Weltbuchs von Schiffahrten. Warhafftige Beschreibung aller vnd mancherley Sorgfeltigen Schiffarten/ auch vile vnbekanten erfundnen landtschafften/Insulen/ Koenigreichen/ vnd Stedten...Durch Ulrich Schmidt von Straubingen/ vnd andern mehr/ sodaselbst in eigener Person gegenwertig gewesen, und salches erfahren. Franckfurt am Mayn (bey Martin Lechler/ in verlegung Sigmund Feirabends vnd Simon Hüters), 1567.] 
Mandioré, Gaiva e Uberaba. No século XVI este porto se converteria no limite da conquista espanhola em águas paraguaias.

Foi justamente a caminho deste porto que Martínez de Irala registrou a dificuldade de reconhecer e dominar a paisagem que seus olhos não abarcavam. Antes de alcançar a Los Reyes, avistara a boca de um riacho que ia do interior até outra lagoa grande; chegando ali, preparou um bergantim e canoas, e mandou um grupo dos seus comandados ir à procura daquela entrada de rio. Apesar de muito procurarem, eles não conseguiram encontrá-la. Intrigado, Martínez de Irala interrogou um indio guarani da sua comitiva e este lhe explicou que

no tempo em que as águas estavam crescidas, corria da dita terra interior um rio até uma lagoa que nela havia, indo para outra lagoa. Porém agora que as águas estão baixas não podiam entrar ali pela pouca água que havia $[\ldots]^{7}$

As palavras que o conquistador registrou, atribuindo-as a um guarani, até onde se pôde averiguar constituem, na literatura ocidental, a primeira descrição dos complexos ecossistemas pantaneiros. Elas explicitam que o centro da América do Sul apresenta uma paisagem banhada por rios e lagoas em constante mutação. Como hoje se sabe, a mais destacada característica do Pantanal é ser um espaço inundável, sujeito à sazonalidade imposta pelo ritmo das águas durante as enchentes, vazantes e secas do rio $\mathrm{Pa}-$ raguai. 0 volume de água no período das cheias desenha um lugar evanescente: existe e já não existe. Foi esta imagem mutável que o índio guarani transmitiu a Martínez de Irala.

Também os escritos de Cabeza de Vaca fazem referência a esta paisagem singular. Segundo suas palavras, em alguns lugares o rio Paraguai se apresentava com tantas bocas que chegava a "perder o remate". A estranheza era tão grande que os próprios índios que ali viviam - afiança o adelantado - não conseguiam reconhecer seu curso e perdiam-se, vagando à deriva ${ }^{8}$.

Estas descrições evidenciam as dificuldades que os espanhóis enfrentavam ao adentrar no complexo fluvial; quase sempre se confundiam, perdendo-se num mundo de tantas águas.

7 MARTÍNEZ DE IRALA, Domingo. Relación de Domingo Martínez de Irala acerca de los descubrimientos que iba haciendo cuando fue navegando Paraguay arriba por orden del gobernador Cabeza de Vaca, desde 18 de diciembre de 1542. Anales de la Biblioteca, Buenos Aires, Biblioteca Nacional, t.8, p.345-346,1912. [tradução da autora].

8 CABEZA DE VACA, Álvar Núñez. Naufragios y comentarios. Madrid: Anaya y Oronoz, 1992. [La relación y comentarios del gouvernador Aluar Nuñez cabeza de vaca, de lo acaescido en las dos jornadas que hizo a las Indias. Valladolid, 1555]. 
Contudo, ao registrar a região aquática de Xarayes, nenhum dos conquistadores do Quinhentos, seus primeiros narradores, a descreve como uma lagoa, mas como um grande espaço entrecortado por rios e lagoas, que já aparece nas descrições como uma paisagem móvel. É fato, porém, que no início dos anos de 1600 ela passa a ser representada em mapas como a Laguna de los Xarayes.

\section{Xarayes na cartografia}

Jaime Cortesão, ao estudar a Ilha Brasil - o mito geográfico criado pelos portugueses com fins geopolíticos - faz diversas referências à lagoa de Xarayes, embora não tivesse como objetivo realizar uma análise da sua cartografia. Para o historiador, a presença de Xarayes nos mapas tem analogia com a de outros lagos míticos, como o de Eupana ou mesmo o do Eldorado. Em apoio aos seus argumentos cita, entre outras cartas, a de Nicolas Sanson de 1650 (Fig. 1), na qual Xarayes se confunde com o Eupana, e a de Nicolas de Fer de 1705, onde a nossa lagoa comunica-se com o rio Tapajós ${ }^{9}$.

Como se pôde constatar, Xarayes é uma construção geográfica absolutamente espanhola, criada a partir dos conquistadores do rio da Prata e divulgada no início do século XVII pelos cronistas das Índias. Mesmo que a sua gestação esteja relacionada a outros lagos, trata-se de uma lagoa independente, desenhada no âmbito do espaço castelhano da América do Sul, cuja imagem figurou nas cartas européias dos séculos XVII e XVIII, excetuando as portuguesas ${ }^{10}$.

A sua origem encontra-se na literatura. Quem lhe deu forma de lagoa foi o espanhol Antonio de Herrera y Tordesillas (1559-1625) - Cronista Mayor de Indias - na sua Historia general de los hechos de los castellanos en las islas i tierra firme del Mar Océano, cujo primeiro volume veio a público em 1601. Ao descrever a região interior do continente sul-americano, encravada na Província do Paraguai de então, Herrera a chamou de Laguna, inserindo-a na geografia que os espanhóis vinham desenhando na América. Em suas palavras:

9 CORTESÃO, Jaime. Raposo Tavares e a formação territorial do Brasil. Lisboa: Portugalia Editora, 1966. 2 v. (1º edição de 1958).

10 COSTA. Maria de Fátima. História de um país inexistente. 0 Pantanal entre os séculos XVI e XVIII. São Paulo: Estação Liberdade, Kosmos, 1999. 
Chama-se este rio na língua dos índios Paranaguazú e comumente Paraná; tem sua entrada e boca no Mar do Meio-dia, desde trinta e cinco graus, até trinta e seis de altura, entre os cabos de Santa Maria, e cabo Branco, que de um a outro terá de boca trinta léguas e dali adentro outras dez léguas de largura, com muitas ilhas no meio, e muitos rios muito grandes, e caudalosos que entram nele pela parte do Oriente, e Ocidente, até o puerto de los Reyes, que é uma lagoa grande que chamam de Los Xarayes pouco menos de 300 léguas do Rio da Prata, aonde entram muitos rios que vêm das vertentes dos Andes, e devem ser os rios que saem nas províncias dos Charcas, e Cuzco, que vão para o Norte, por onde entra outro braço caudaloso da dita Laguna, que há dado ocasião a pensar que este Rio se comunica com o de S. Juan de las Amazonas, e outros dizem, que sai da lagoa do Dourado, que é quinze jornadas da de los Xarayes, ainda há opiniões que não há Dourado [... $]^{11}$

Foi a partir deste escrito que o Ocidente passou a identificar a Laguna de los Xarayes com o porto que Martínez de Irala havia denominado de Los Reyes, e a descrevê-la como um fenômeno originado das abundantes águas que formavam os rios Paraná e da Prata, relacionando-a - tal como o citado cronista - com o lago do Eldorado. Assim descrita, logo Xarayes ganhou forma cartográfica: a transposição de texto a traço foi realizada pouco tempo depois, mas fora de Espanha; é fruto do trabalho dos cartógrafos neerlandeses.

Xarayes efetivamente passou a fazer parte da cartografia mundial no início da década de 1630, quando seu desenho foi estampado no mapa Paraguay, Ó prov. de Rio de la Plata cum regionibus adiacentibus Tucuman et Sta. Cruz de la Sierra, e pôde ser vista nos Atlas publicados concomitantemente pelas casas editoriais de W. J. Blaeu (Fig. 2) e J. Janssonius. Contudo, não foram estes cartógrafos os autores do seu desenho; quem deu contornos mapográficos à lagoa sul-americana foi Jodocus Hondius II. E aqui cabe uma história de bastidores: Hondius II era cunhado de Janssonius, ambos rivais de Blaeu. Antes de falecer, porém, em 1629, Hondius vendeu a Blaeu um lote de pranchas de cobre gravadas com desenhos de alguns dos seus mapas, dentre os quais o da Província do Paraguai. Janssonius deplorou o fato e, tentando remediar a perda, procurou os gravadores e lhes encomendou reproduções dos antigos desenhos vendidos a Blaeu.

11 HERRERA, Antonio de. Historia general de los hechos de los castellanos en las islas i Tierra firme del mar océano. [S.1.]: Imprenta Real, por Juan Filmeco, 1601. t. I. , cap. XXIIII, p. 70. tradução e grifos da autora. 
Desta forma, tanto Janssonius como Blaeu passaram a possuir e publicar cópias idênticas dos mapas desenhados por Hondius II $^{12}$.

No verso do desenho referente à Província do Paraguai, Blaeu fez imprimir um texto em latim narrando sinteticamente a história daquela nova região. A leitura deste texto permitiu identificar a fonte usada pelo autor do mapa à hora de desenhar o Paraguai e Tucumã: as páginas de Antonio de Herrera.

Mesmo que a seqüência temática não seja totalmente idêntica, ao se comparar o trecho da Historia general acima citado, com o texto impresso no Atlas, é fácil reconhecer as suas semelhanças, principalmente quando este último declara:

salpicado freqüentemente por muitas ilhas recebendo muitos riachos deste lado do Oriente, daquele do Ocidente até o Porto 'de los Reyes' que é um lago de vasta magnitude (chamam de Los Xarays) afastado de pouco menos de trezentas milhas até a desembocadura, ao qual constituem e aumentam rios que caem dos montes 'Andes.'13

Vê-se, pois, que o desenho do mapa corresponde à narrativa do cronista espanhol. Assim, baseado na descrição de uma lagoa que surgira na interpretação de Antonio de Herrera, as casas cartográficas neerlandesas criaram um modelo de desenho para o interior sul-americano. Desde então esta representação da lagoa de Xarayes foi levada aos grandes mapas europeus dos séculos XVII e XVIII, com exceção dos portugueses.

Ao incorporar informações sobre terras desconhecidas, essas cartas fizeram com que Xarayes fosse vislumbrada em

12 KROGT, P. van der (Ed.). Koeman's atlantes neerlandici. The folio atlases published by Gerard Mercator, Jodocus Hondius, Henricus Hondius, Johannes Janssonius and their successors. MS 't Goy-Houten: Hes \&t de Graaf Publishers, 1997. p. 73 et seq.

Guillermo Furlong - jesuita e historiador argentino - em seus livros Cartografia jesuitica del Rio de la Plata (1936) e Los jesuitas y la cultura rioplantense (1946) dá a entender que a concepção do mapa Paraguay, Ó prov. de Rio de la Plata cum regionibus adiacentibus Tucuman et Sta. Cruz de la Sierra é obra do padre Diego de Torres, sem contudo trazer qualquer referência que embase sua observação. E ao ilustrar esta afirmativa faz uso do mapa publicado por Blaeu. Há de se levar em conta também que os inacianos durante muito tempo - como se verá adiante - acreditaram que Xarayes era a mãe do rio Paraguai e assim a representaram nos seus mapas, portanto, distintamente do que se vê no desenho holandês.

13 BLAEU, W. J. Paraguay, Ó prov. de Rio de la Plata cum regionibus adiacentibus Tucuman et Sta. Cruz de la Sierra, 1631. In: BLAEU, W. J. Appendix Theatri A. Ortelli et Atantis G. Mercatoris, continens tabulas geographicas diversarum Orbis regionum, nunc primus editas cum descriptionibus. Amsterdã, 1631. tradução e grifos da autora. 
mundos distantes. Por meio delas ficou-se sabendo que no interior da América Meridional havia um fabuloso lago ou lagoa, cujas margens eram habitadas por indígenas possuidores de ouro e prata. Para dar destaque aos fatos geográficos publicados, os associavam às crônicas e a estudos coevos, declarando suas fontes no próprio corpo dos mapas como, por exemplo, na Carta Geográfica Del Brasil (s/d) de Giovanni Battista Albrizzi (Fig.3).

Apesar de ser a mais difundida, esta não foi a única representação cartográfica que Xarayes recebeu. No final do século XVII surgem os mapas jesuíticos como outra fonte para o conhecimento do espaço sul-americano.

\section{Xarayes e os mapas inacianos}

Depois de instalarem suas missões, os religiosos da Companhia começaram também a cartografar a Província Jesuítica do Paraguai e o espaço do Chaco onde atuavam.

A representação jesuítica do Paraguai segue, grosso modo, um traçado comum que pode ser considerado o modelo típico das cartas das missões paraguaias. Seu desenho tem como eixo o rio Paraguai e, dentro dele, descreve a província jesuítica localizando todas as suas reduções, os povos indígenas, os meandros e cursos fluviais, indicando ainda as diferenças de relevo. Embora vivendo na região, os inacianos também incluíram em seus mapas a lendária Laguna de los Xarayes, enriquecendo-a com um novo elemento: a Isla de los Orejones, como se pode observar no mapa de Ioannes Petroschi, de 1732 (Fig. 4).

Nele se percebe que o rio Paraguai surge em Xarayes, representada como uma enorme lagoa, cujo interior guarda a Ilha dos Orelhões.

Ao incluir esta ilha na representação cartográfica da Província paraguaia, os jesuitas deixam perceber que sua fonte não foi a mesma que os holandeses utilizaram, pois esta ilha não consta do livro de Herrera. 0 novo acidente geográfico encontra-se, sim, numa fonte estritamente sul-americana, a saber, as páginas de La Argentina, de autoria de Ruy Díaz de Guzmán, cronista nascido em Assunção, que as escreveu no final do século XVI. Trata-se da primeira crônica histórica sobre a região do Prata-Paraguai.

Em La Argentina, Guzmán informa que os orelhões viviam "numa ilha que faz este rio [o Paraguai] de mais de dez léguas de comprimento e duas e três de largura", que esta ilha tinha uma "ameníssima terra abundante de mil gêneros de frutas silvestres", dentre elas "uvas, peras e azeitonas". Segundo ele, esses índios tinham toda a ilha ocupada de sementeiras e 
chácaras, "e em todo o ano" plantavam e colhiam "sem fazer diferença de inverno nem verão." Esses ilhéus eram pessoas "de boa vontade e amigos dos espanhóis.” E atesta: “[...] chamaram os antigos a essa ilha o Paraíso Terreal, por sua abundância e maravilhosas qualidades que tem [...]"14.

Vale porém observar que La Argentina circulava somente em território espanhol da América Meridional e em exemplares manuscritos. A obra só foi publicada em Buenos Aires em 1835; no início do século XIX algumas cópias manuscritas foram levadas à Europa pelos demarcadores Félix de Azara e Juan Francisco Aguirre.

Este dado ajuda a entender porque a Ilha dos Orelhões - ou do Paraíso - é inerente à cartografia jesuítica. Foram estes religiosos que no Paraguai tomaram conhecimento do manuscrito de La Argentina e da sua geografia. Isto é confirmado, por exemplo, pelos escritos dos padres Francisco de Arce e Bartolomeu Ximenez que seguidamente se referem a Xarayes e à Ilha dos Orelhões ao descreverem as viagens que realizaram pelos rios alto-paraguaios na busca do caminho fluvial que os levasse até Chiquitos ${ }^{15}$. Por sua vez, aqueles acidentes geográficos também estão presentes nos textos dos padres Lozano ${ }^{16} \mathrm{e}$ Guevara $^{17}$, o que demonstra que estes religiosos foram leitores atentos da obra de Díaz de Guzmán.

Contudo, a mais difundida carta jesuítica do Paraguai não estampou nem a famosa laguna nem a sua ilha. Trata-se do mapa desenhado em 1749 pelo padre José Quiroga, intitulado Mapa de las Missiones de la Compañia de Jesvs (no subtítulo, complementa: nos rios Paraná e Uruguay conforme às mais modernas observações de latitude e de longitude feita nos povos

14 DÍAZ DE GUZMÁN, Ruy. La Argentina. Madrid: Historia 16, 1986. p. 81-82, tradução da autora.

15 ARCE, Francisco de. Relação duma viagem no Rio Paraguai desde Assunção até o Lago de Xarayes, em 1703-1704, pelo padre Francisco de Arce, redigida em 1713 apud CORTESÃO, Jaime (Org.). Manuscritos da coleção De Angelis. Antecedentes do Tratado de Madri. Rio de Janeiro: Biblioteca Nacional, 1955. t. 6. p. 23-34; XIMENEZ, Bartolomeu. Relação duma viagem de exploração no rio Paraguai com o fim de estabelecer ligação com as missões dos Chiquitos pelo padre Bartolomeu Ximenez 1703 apud CORTESÃO, Jaime (Org.). Manuscritos da coleção de Angelis. Antecedentes do Tratado de Madri. Rio de Janeiro: Biblioteca Nacional, 1955. t. 6. p. 35-54.

16 LOZANO, Pedro. Historia de la conquista del Paraguay, Rio de la Plata y Tucuman. Buenos Aires: Imprenta Popular, 1873-1875. 4 v.

17 GUEVARA, Padre. Historia del Paraguay, Rio de La Plata y Tucuman. Buenos Aires: Imprenta del Estado, 1836. (Colección Pedro De Angelis). 
de ditas Missões, e [baseadas] nas relações antigas e modernas daqueles padres Missionários de ambos os rios - tradução da autora) (Fig. 5), que Furlong considerou a mais perfeita carta que fizeram os jesuítas no século XVIII ${ }^{18}$.

Quiroga era cartógrafo e matemático respeitado, tendo participado, em 1745, da primeira expedição espanhola de exploração da Patagônia e depois, em 1753-1754, da Terceira Partida de Limites que percorreu a região do Alto Rio Paraguai, por força do estipulado em 1750, no Tratado de Madrid. Estas qualificações dão credenciais ao seu desenho cartográfico. 0 mapa foi produzido para ilustrar a obra do padre Pedro Lozano, Historia de la Compañia de Jesús de la Provincia del Paraguay, publicada em Madrid em $1755^{19}$.

$\mathrm{Na}$ verdade, o corte realizado por Quiroga na sua representação deixou Xarayes e sua ilha fora dos limites do mapa, mas isto não excluiu a lagoa do seu referencial. Na parte superior direita, ele registrou:

0 rio Paraguai tem sua origem no lago dos Xarayes, na Latitude de 14 graus ao Sul da Equinocial. Entram neste lago pela banda do Poente os rios Ycipotiba e Yauri, os quais vêm do Noroeste[;] por qualquer um deles dois os Portugueses, vão às novas minas de Mato Grosso situadas na ribeira Setentrional do Yauri, quase ao Oeste das outras minas de Cuiabá. [Tradução da autora]

A existência da lagoa fazia, portanto, parte do universo cartográfico do autor. Ao considerá-la nascedouro do Paraguai e declarando-o na carta que seria a representação oficial da Província Jesuítica, Quiroga, respeitado cartógrafo e matemático, conhecedor da região que registrava com modernos instrumentos científicos em contínuas observações, reconhecia efetivamente o mito como fato geográfico.

\section{Xarayes e os monçoeiros}

Já em inícios do século XVIII, a região começou a ser conhecida como o Pantanal. A denominação foi cunhada pelos mamelucos paulistas, que, seguindo as rotas abertas no final

18 FURLONG, Guillermo. Cartografía jesuitica del Rio de la Plata. Buenos Aires: Facultad de Filosofia y Letras, 1936.

19 Ibid. 
do século anterior pelos bandeirantes, continuavam a ignorar os limites fixados em 1494 pelo Tratado de Tordesilhas, adentrando pela bacia do Alto Rio Paraguai e avançando em terras espanholas. Mais ao norte não encontraram cidades fabulosas ou reinos encantados, tão sonhados pelos conquistadores do século XVI, mas sim palpáveis e lucrativos veios de ouro. Denominaram a região Minas do Cuiabá.

Para o comércio e a comunicação destas novas minas foram empreendidas expedições fluviais conhecidas como Monções.

Utilizando canoas de tecnologia indígena, os monçoeiros saíam de São Paulo pelo rio Tietê e cruzavam as águas da bacia paraguaia, até alcançarem as Minas do Cuiabá (Fig. 6). Era uma viagem longa, difícil e perigosa. Ao atravessarem a parte mais inundável do roteiro e não conhecendo a suposta Laguna de los Xarayes nem a sua Ilha do Paraíso, deram-lhe o nome de Pantanal.

Analisando as narrativas destes viajantes pode-se perceber que o termo Pantanal ou Pantanais foi criado como uma palavra-conceito; com ele os mamelucos paulistas denominaram a paisagem singular da bacia alto-paraguaia, no espaço compreendido entre os rios Taquari e Cuiabá. E definiram pantanais como "campos alagados com várias lagoas e sangradouros" são vargens dilatadas, ricas em fauna terrestre e aquática e um território dominado pelos índios Payaguá e Guaikurú.

Durante alguns anos, a castelhana Laguna de los Xarayes conviveu com o luso-brasileiro Pantanal. Porém, pouco a pouco, essas imagens foram se identificando até que os "campos alagados" se sobrepuseram à mítica lagoa. E logo o mistério de Xarayes seria desfeito. Isto aconteceu como resultado das observações práticas de jesuitas e pela ação dos demarcadores de limites, com as primeiras observações científicas determinadas inicialmente pelo Tratado de Madrid (1750) e depois, pelo de Santo Ildefonso (1777). Elas demonstraram que a afamada Laguna de los Xarayes nada mais era que o rio Paraguai espraiado.

Isto, entretanto, não se fez sem uma animada disputa científica entre inacianos e demarcadores.

\section{De Xarayes ao Pantanal}

As primeiras referências ao fim da Laguna de Xarayes estão relacionadas ao Tratado de Madrid e à Terceira Partida de

20 PALÁCIO, Francisco. Roteyro da viagem de São Paulo para as Minas do Cuyabá que fez Francisco Palácio no ano de 1726. Mss. 1734. Códice Yan de Almeida Prado (doravante, Códice Yan) 31, Instituto de Estudos Brasileiros, Universidade de São Paulo. (p. 17v; ortografia foi atualizada). 
Limites que, por força deste acordo, esteve na região entre 1753 e 1754. No Diário de viagem os Comissários de Limites escreveram: “[...] Pântanos que formam as enchentes do rio Paraguai, chamados a Lagoa de Xarayes, como se refere o Artigo VI [do Tratado]"21, o que leva a pensar que o reconhecimento da $L a-$ guna de los Xarayes teve pouco relevo durante aqueles trabalhos. Já o testemunho do jesuíta José Guevara, em sua Historia del Paraguay, Rio de la Plata y Tucuman, deixa claro que logo no início daquela expedição os demarcadores desfizeram a magia da grande lagoa. Sobre isto escreveu o religioso:

Um desengano completo sobre a laguna de Xarayes se conseguiu com a expedição que se fez no ano de 1753, rio Paraguai acima. Alguns lhe davam cem léguas, de norte a sul, e dez de oriente a poente; outros mais liberais em alargar que em lidar com medidas, a estendiam cem léguas a todos ventos. Porém na realidade, esse espaçoso pedaço de terra que está entre a serra de Chiane, Morro Escarpado e rio de Cuiabá, quase desde os dezesseis até os dezoito graus, não é outra coisa senão um terreno baixo que se inunda no tempo de águas, com as vertentes da serra de Cuiabá e com o derramamento do Paraguai em tempo de crescentes $[. . .]^{22}$

Quiçá pela própria celeuma que envolvia os trabalhos relacionados ao cumprimento do Tratado de Madrid, isso parece não ter sido assimilado à época. E uma vez que em 1761 se anulou esse acordo, a questão só voltou a lume quando outra expedição demarcadora -também chamada Terceira Partida de Limites - foi enviada à região por força do Tratado Preliminar assinado em Santo Ildefonso em 1777. Cabe salientar que diferentemente da Partida dos anos de 1750, na qual portugueses e espanhóis trabalharam conjuntamente, a nova comissão sequer chegou a se reunir. De um lado, ficaram os expedicionários espanhóis e, de outro, os portugueses, ambos reconhecendo a seu modo as terras fronteiriças, sem que fosse acordado um conjunto documental comum. Mas as duas partes empenharamse em compreender os mistérios da famosa lagoa; como resultado temos, por exemplo, o relato que o espanhol Felix de Azara publicou em 1809, e a memória Noticias do Lago Xarayes escrita

21 Mss. Instituto de Estudos Brasileiros, Códice Yan 11.

22 GUEVARA, Padre. Historia del Paraguay, Rio de La Plata y Tucuman. Buenos Aires: Imprenta del Estado, 1836. p.55. (Colección Pedro De Angelis); tradução e grifos da autora. 
pelo luso-brasileiro Antonio Pires da Silva Pontes Lemos, que ainda se mantém manuscrita ${ }^{23}$.

E, no início do século XIX, passou-se a atribuir a Félix de Azara a compreensão objetiva do espaço geográfico sul-americano e a desmistificação de Xarayes. Em suas palavras,

[...] o lago de Xarayes existe pelo concurso de todas as águas produzidas pelas chuvas abundantes que caem entre os meses de novembro e fevereiro nas regiões de Chiquitos e em todas as montanhas onde nascem os formadores do rio Paraguai [...]

Para ele o rio Paraguai,

não podendo conter todas estas águas no seu leito, as estende de um lado a outro, porque o país é plano. Como estas chuvas são muito mais consideráveis em alguns anos que em outros, o lago segue em sua extensão, e como sua figura ou seu contorno depende da horizontalidade do terreno, este lago é também extremamente irregular e é impossível descrevê-lo com exatidão. Para dar uma idéia aproximada agora falarei da sua extensão a leste do rio Paraguai, e passarei em seguida ao outro lado.

E continua:

Alguns antigos acreditavam que o lago era a fonte do rio do Paraguai, e é precisamente o contrário. Outros, aficionados a forjar contos, disseram que no centro do lago há o império de Xarayes, ou do Dourado, ou de Paytiti, e embelezaram esta mentira com outras fábulas ainda mais estranhas. ${ }^{24}$

À época, as palavras de Azara foram tomadas como angulares e, pela grande difusão de sua obra, acreditou-se ter sido ele quem desvelou os mistérios de Xarayes, descrevendo-a como um acidente geográfico sazonal. Porém, como se disse há pouco, antes dele os jesuítas já haviam chegado a esta conclusão e é provável que Azara, desafeto dos inacianos, tivesse conhecimento disto.

23 Conservam-se duas cópias deste documento, uma no acervo da Biblioteca Nacional do Rio de Janeiro (Mss. I, 32, 20, n. 5) e outra na British Library (Add. Ms. 15191, f. 80). Esta questão está tratada com detalhes em COSTA. Maria de Fátima. História de um país inexistente. 0 Pantanal entre os séculos XVI e XVIII. São Paulo: Estação Liberdade, Kosmos, 1999. p. 218 et seq.

24 AZARA, Felix. Viajes por la América Meridional. Madrid: Espasa-Calpe, 1969. p.58-59; tradução e grifos da autora. Versão original: Voyages dans l’Amérique méridionale, par don Félix de Azara. Paris: Dentu, 1809. 
0 jesuíta Martin Dobrizhoffer, em seu História dos Abipones, publicado pela primeira vez, em latim, em Viena em 1784, já havia se manifestado sobre essa questão. Com base nas observações do também inaciano J. Sánchez Labrador, Dobrizhoffer escreveu:

Hoje em dia só é o certo que erraram todos aqueles que dão ao rio uma origem desde a Laguna de los Xarayes. Este erro antigo e geral [...] de nenhum modo foi levado à Europa por geógrafos jesuitas, mas pelos primeiros espanhóis que conquistaram o Paraguai. Sua origem foi encontrada em nossa época. Agora se sabe que os espanhóis que mais tarde navegaram pelo rio, chegaram ainda sessenta léguas mais acima da mencionada Laguna. Daí resulta que a origem do Paraguai deve buscar-se nas regiões mais longínquas, para o leste ou o norte. Alguns acreditam hoje tê-lo encontrado no Eldorado. [...] Seja como for, fica bem estabelecido que o Paraguai não nasce na laguna de los Xarayes e que esta laguna só existe nos mapas, pois é a reunião de águas que às vezes se vê por lá, não é a mãe, mas sim a filha do Paraguai. Isto eu afirmo sem titubeio e me baseio na autoridade histórica do Pe. Sánchez Labrador. ${ }^{25}$

Estas informações são confirmadas pelo novo traçado do rio Paraguai que apareceu no mapa manuscrito do próprio Sánchez Labrador, desenhado provavelmente no início dos anos de 1770 (Fig. 7), para ilustrar o seu Diario o relación fragmentaria de los viajes desde la Reducción de Nuestra Señora de Belén hasta las misiones de Chiquitos, 1766-1767 ${ }^{26}$.

0 mapa mostra o curso do rio Paraguai e dos seus afluentes e marca a diferença de relevo no entorno daquele rio. Também assinala as terras correspondentes às águas de Xarayes e sua área de expansão desde o Jauru até próximo à desembocadura do Taquari. No desenho, Sánchez Labrador fez o Paraguai romper o antigo limite de Xarayes, desenhando seu curso superior e dando-lhe as suas verdadeiras nascentes.

Vale contudo lembrar, com base no trecho do Diário dos demarcadores de 1753-1754, que àquela época o mistério de Xarayes já havia sido desfeito, ou seja, antes da viagem daquele

25 DOBRIZHOFFER, Martín. Historia de los abipones. Resistencia. (Chaco): Universidad Nacional del Nordeste, 1967. v. I, p. 278-279 (tradução e grifos da autora). (título original: Historia de Abiponibus equestris bellicosaque Paraguariae nationae. Viena, 1784).

26 Este diário foi publicado no início do século XX sob o título de SÁNCHEZ LABRADOR, José. El Paraguay católico. Buenos Aires: Imprenta de Coni y Hermanos, 1910-1917. 3 v. 
jesuíta. Segundo o Diário, são as enchentes do rio Paraguai que formam os pântanos "chamados a Lagoa de Xarayes", fato referendado com mais veemência pelo padre Guevara em sua Historia, ao observar que aqueles demarcadores sofreram um desengano completo ao chegarem a Xarayes: não era "outra coisa, que um terreno baixo que se inunda em tempo de águas, com as vertentes da serra de Cuiabá, e com o derramamento do Paraguai em tempo de crescentes." 27

Voltando a Dobrizhoffer, certo é que não foram os jesuítas os criadores do mito geográfico da Laguna de los Xarayes. Contudo, os seus mapas como, por exemplo, o de José Quiroga (Fig. 5), enfaticamente confirmavam esta construção, sendo eles, portanto, seus grandes difusores. Mas, por seu turno, os inacianos também muito contribuíram para desfazer o mistério, percebendo a singular dinâmica das águas paraguaias. Notaram, antes que outros, que Xarayes nada mais era que o espraiamento deste grande rio. E o próprio Dobrizhoffer apresentou no seu livro a nova representação objetiva da região (Fig. 8); no antigo lugar onde estava Xarayes escreveu: "Inundações dos vastos territórios pela enchente anual do rio; espaço que em outros tempos chamou-se Lago de Xarayes.”

Vale frisar, entretanto, que mesmo antes desta época, e alheios às discussões travadas entre religiosos e demarcadores, os luso-brasileiros que regularmente transitavam pela região, a haviam chamado Pantanal: lugar, conforme bem definiu o monçoeiro João Antonio Cabral Camello em 1727 de "vargens muito dilatadas, que começando no meio do Taquari, vão acabar quase junto do mesmo rio Cuiabá." ${ }^{28}$

No horizonte histórico o Pantanal aparece, pois, como uma invenção luso-brasileira, nascida da prática dos monçoeiros que por ali trafegavam no início do Setecentos. A palavra também traz consigo um forte significado geopolítico. Ao suplantar a castelhana Xarayes como designativo das terras molhadas do interior sul-americano, o topônimo Pantanal veio afirmar a supremacia luso-brasileira na região.

Recebido em: 4 Abr. 2007 Aprovado em: 22 Maio 2007

27 GUEVARA, Padre. Historia del Paraguay, Rio de La Plata y Tucuman. Buenos Aires: Imprenta del Estado, 1836. p. 55. (Colección Pedro de Angelis). Tradução e grifos da autora.

28 CAMELLO, João Antonio Cabral. Noticias Práticas das Minas do Cuiabá e Goiases na Capitania de S. Paulo e Cuiabá, que dá ao Rev. Padre Diogo Juares, o Capitão João Antonio Cabral Camello, sobre a viagem que fez às Minas do Cuiabá no ano de 1727 apud TAUNAY, Visconde de. Relatos monçoeiros. São Paulo: Comissão do IV Centenário da Cidade de São Paulo, Livraria Martins Editora, 1953. p. 118. 
Figura 1: Nicolas Sanson, Amérique Méridionale, 1650. INSTITUT0 CULTURAL BANCO SANTOS. O tesouro dos mapas. A cartografia na formação do Brasil. São Paulo, 2002. CD-ROM.

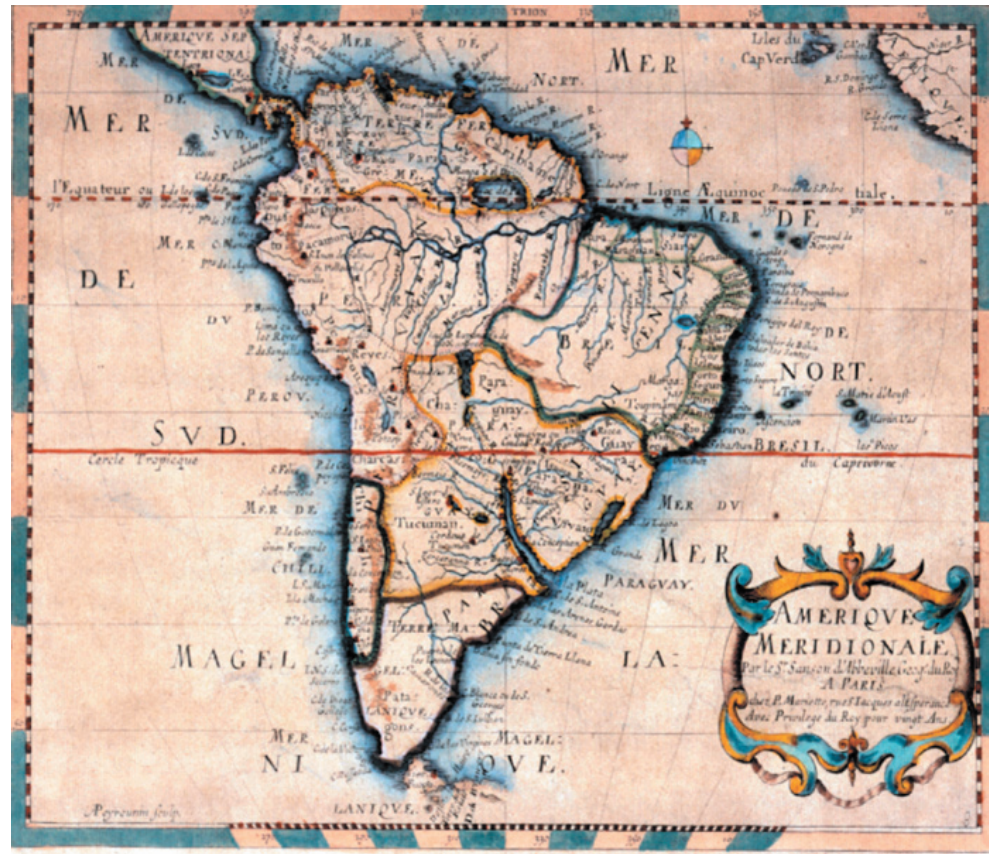


Figura 2. W. J. Blaeu. Paraguay, Ó prov. de Rio de la Plata cum regionibus adiacentibus Tucuman et Sta. Cruz de la Sierra, 1631. In: BLAEU, W. J. Appendix Theatri A. Ortelli et Atantis G. Mercatoris, continens tabulas geographicas diversarum Orbis regionum, nunc primus editas cum descriptionibus. Amsterdã, 1631.

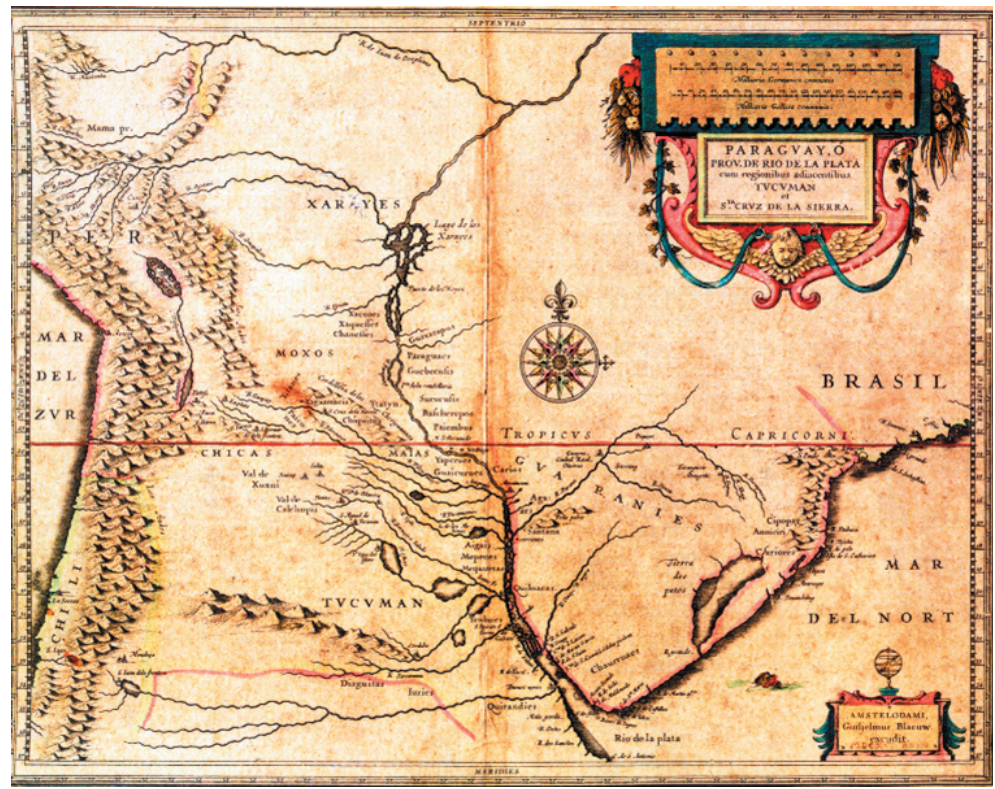


Figura 3. Giovanni Battista Albrizzi, Carta geográfica del Brasil, s/d (ca. 1750). INSTITUTO CULTURAL BANCO SANTOS. 0 tesouro dos mapas. A cartografia na formação do Brasil. São Paulo, 2002. CD-ROM.

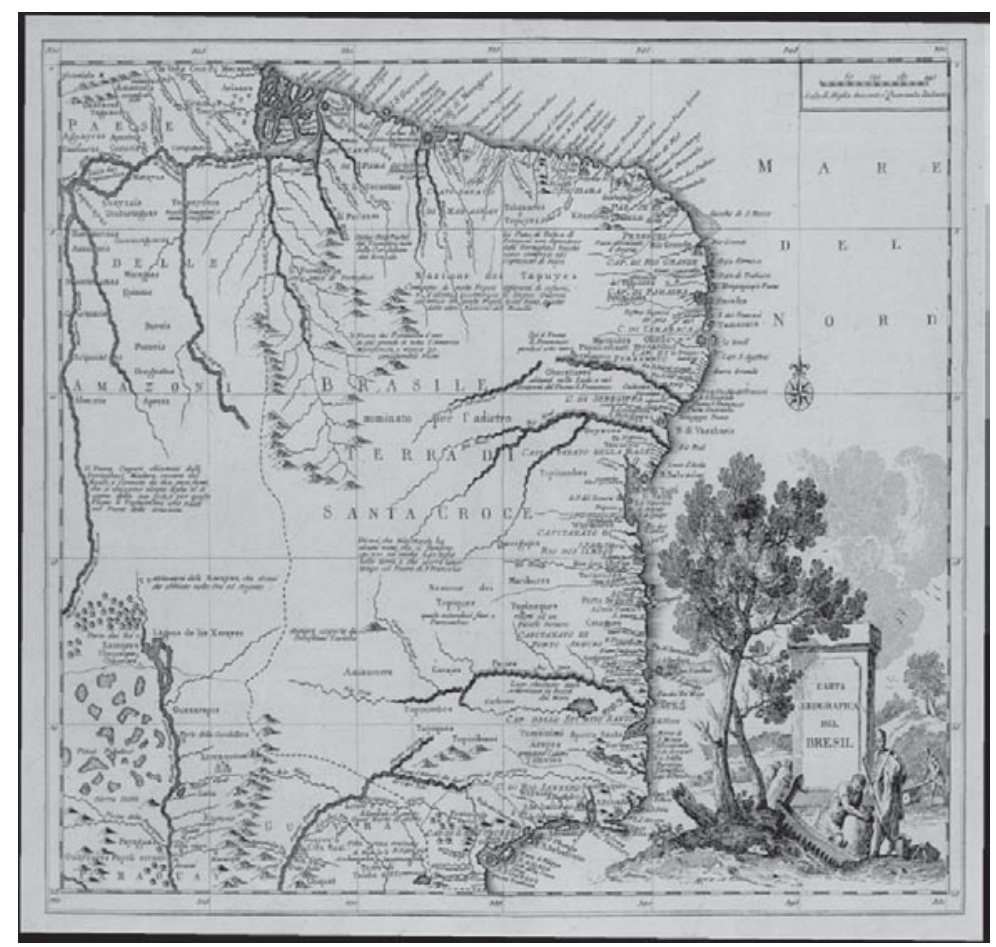


Figura 4. Ioannes Petroschi. Paraquare Provincie Soc. Jesu Cum Adiacentib Novissima, 1732. INSTITUTO CULTURAL BANCO SANTOS. 0 tesouro dos mapas. A cartografia na formação do Brasil. São Paulo, 2002. CD-ROM.

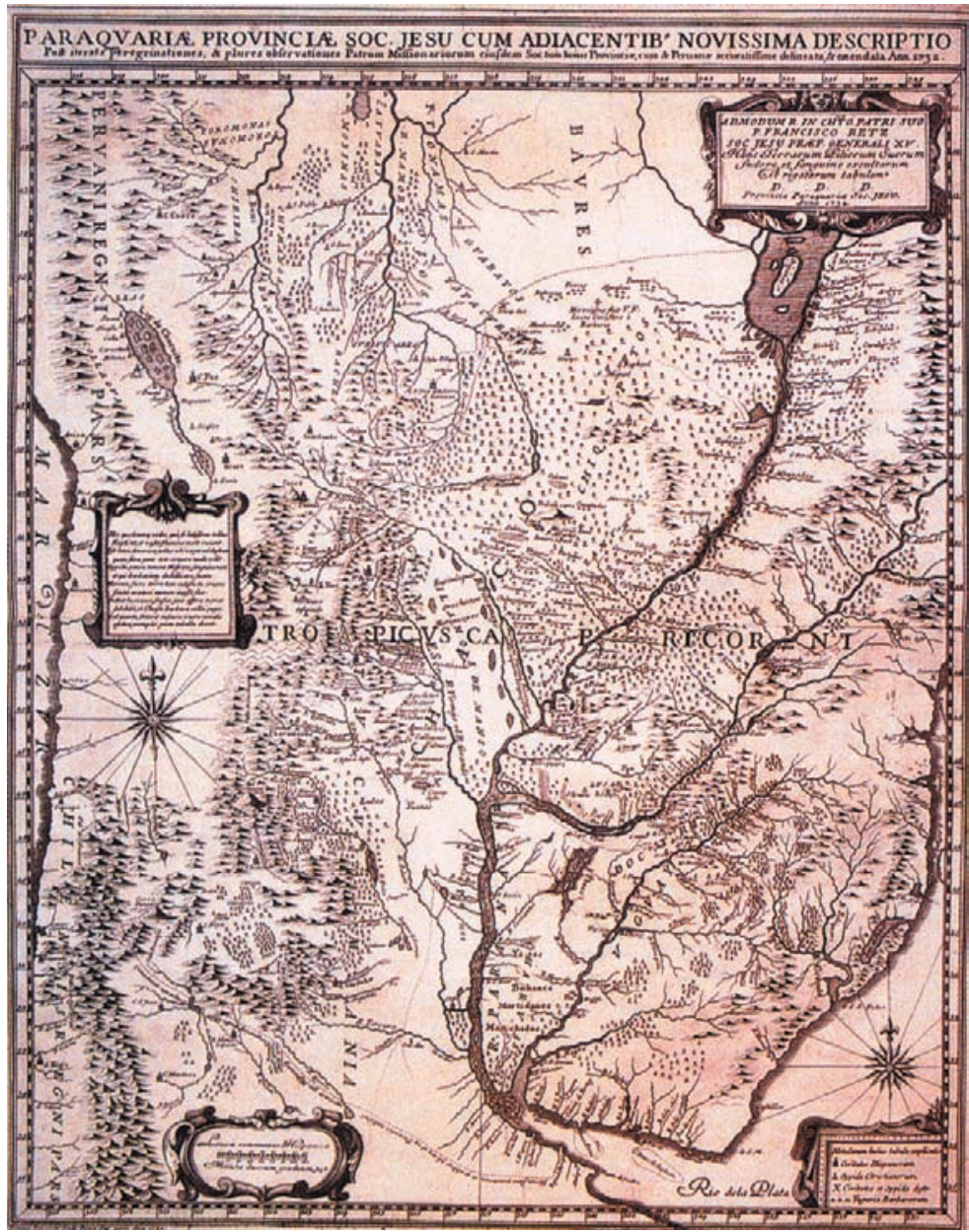


Figura 5. José Quiroga. Mapa de las Missiones de la Compañía de Jesvs. 1749. Archivo Histórico Nacional, Madrid, códice. Estado. Proc. Leg. 3505. Sig 682.

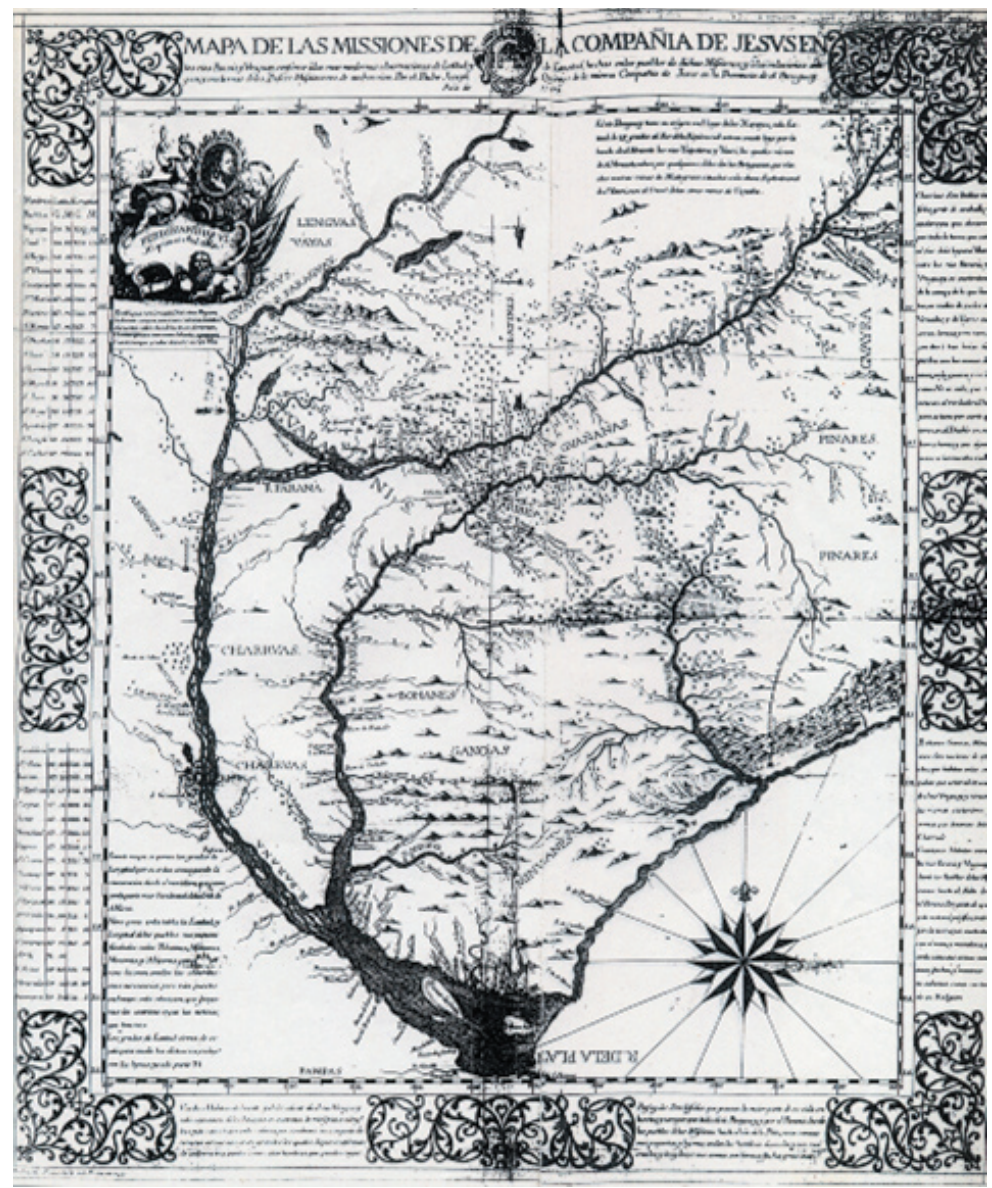


Figura 6. Anônimo. Parte da Capitania de Matto Grosso q. compreende o Cuyavá tirado de hum Mappa 0 . dela veio, com a navegação de S. Paulo. [Detalhe] Ca. 1780. IEB. Códice Yan, 23, no. 10, f. 13).

Foto Pablo Diener.

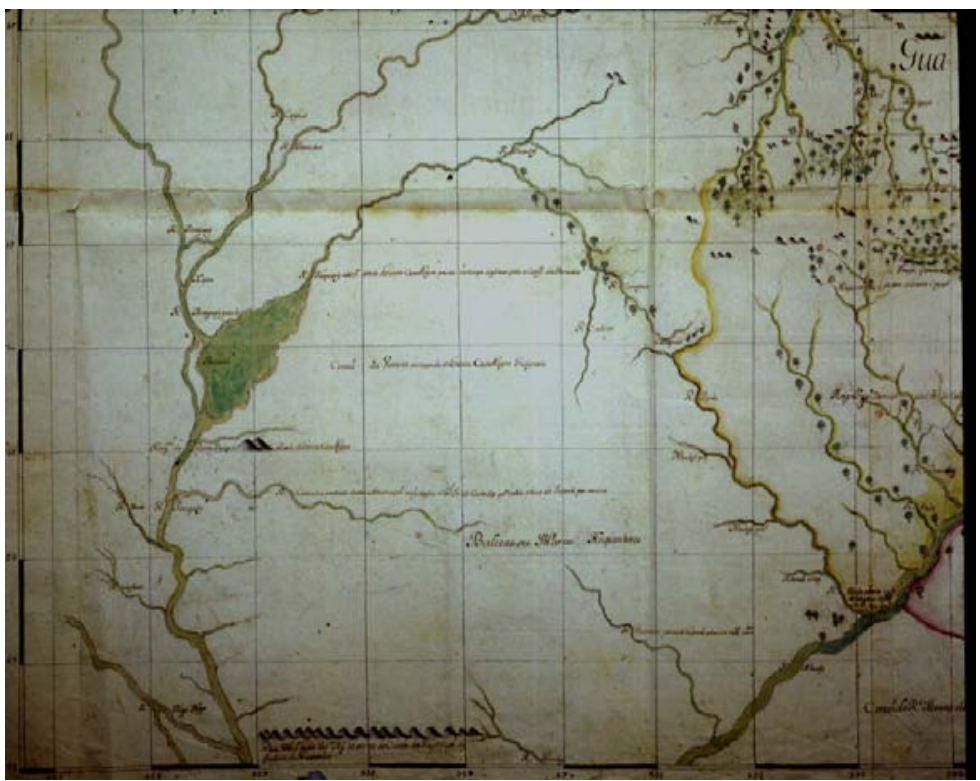


Figura 7. Sánchez Labrador, Rio Paraguai, ca. 1770. El Paraguay Católico. Buenos Aires: Imprenta de Coni y Hermanos, 1910.

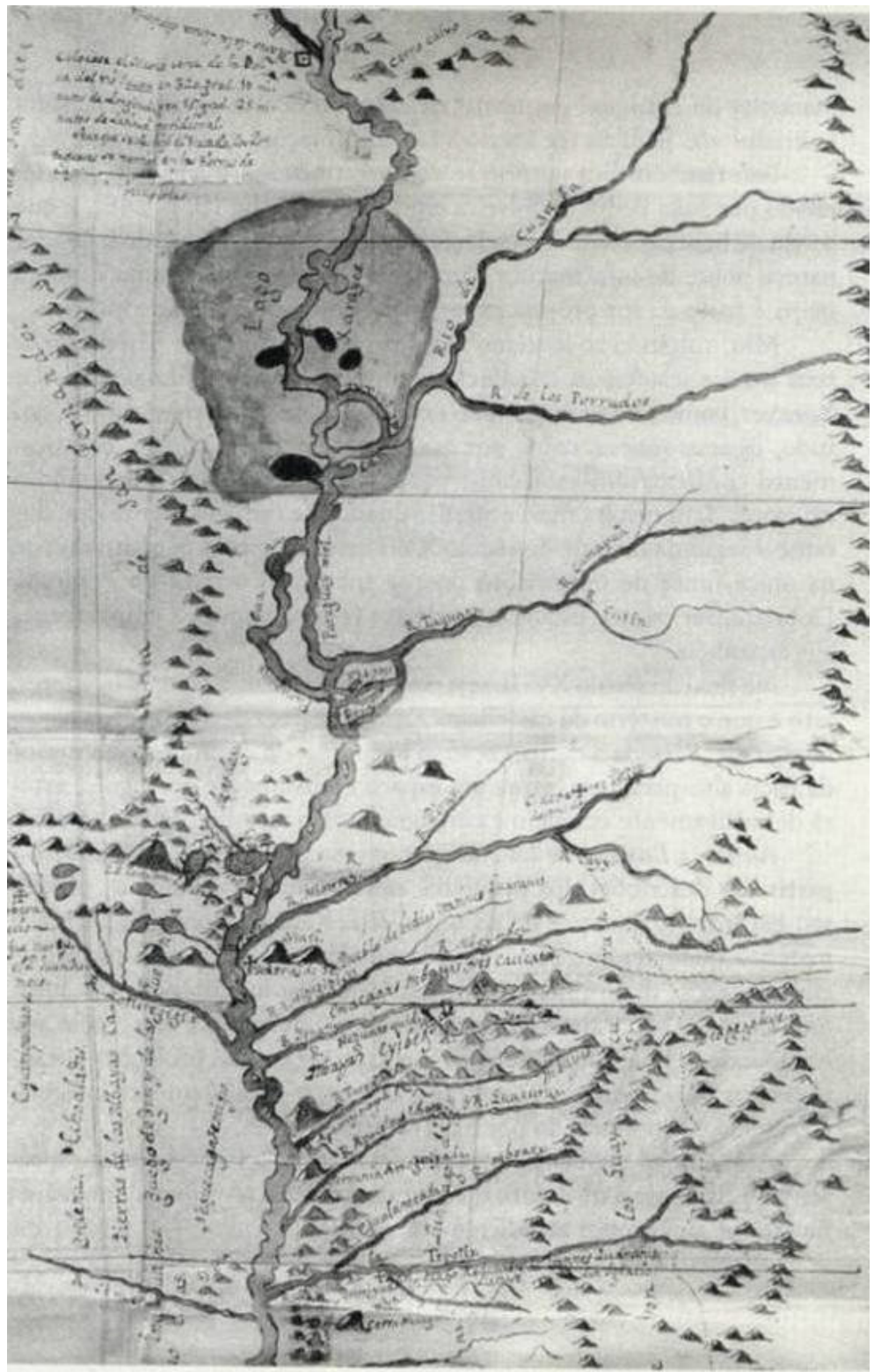


Figura 8. Martin Dobrizhoffer, Mappa Paraquariae in multis a me correcta. Quid si in pluribus porro peralios corrigenda. Authore M. D. eius provinciae Misionario, ca. 1780. Historia de los abipones. Resistencia (Chaco): Universidad Nacional del Nordeste, 1967.

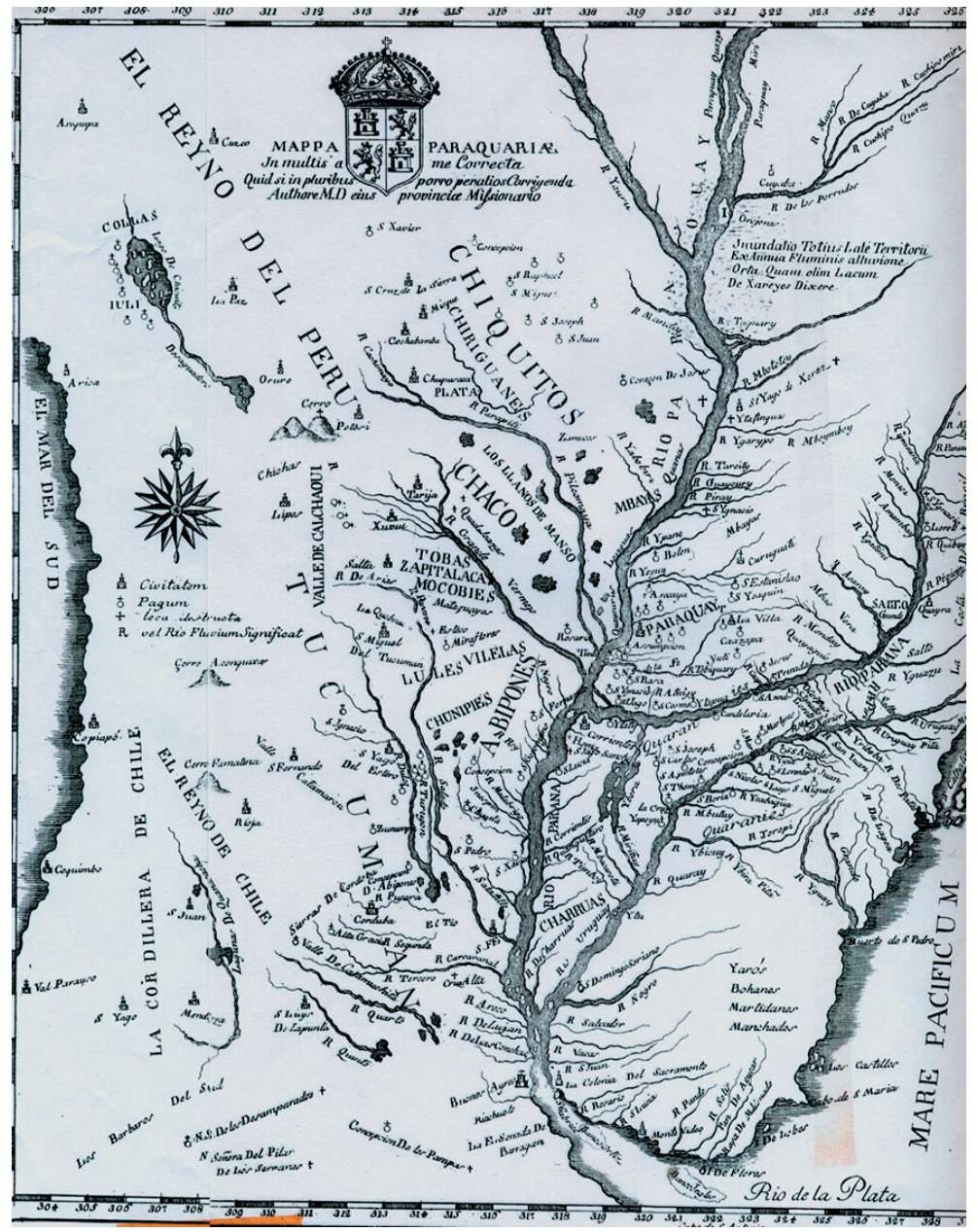

